declared, Angela Zink Speakers bureau: Speakers fees from AbbVie, Janssen, Pfizer, Roche, Sanofi, Anja Strangfeld Speakers bureau: Speakers fees from Bristol-Myers Squibb, MSD, Pfizer, Roche DOI: 10.1136/annrheumdis-2019-eular.3039

\section{THU0099 DEVELOPMENT OF A NEW PATIENT-GENERATED OUTCOME MEASURE TO IDENTIFY DISEASE-SPECIFIC DISTRESS IN PEOPLE WITH RHEUMATOID ARTHRITIS}

Linda Silke ${ }^{1}$, Othman Kirresh ${ }^{2} J a c k i e ~ S t u r{ }^{3}$ Heidi Lempp ${ }^{4}{ }^{1}$ King's College London, Academic Department of Physiotherapy, London, United Kingdom; ${ }^{2}$ King's College London, Academic Department of Rheumatology, London, United Kingdom; ${ }^{3}$ King's College London, Florence Nightingale Faculty of Nursing and Midwifery, London, United Kingdom; ${ }^{4}$ King's College London, Department of Inflammation Biology, London, United Kingdom

Background: Rheumatoid Arthritis $(\mathrm{RA})$ is a progressive inflammatory disease which causes pain, joint damage and disability. Patients with RA may experience psychological distress in addition to their physical symptoms. They may also experience disease-specific distress (DSD), which is related to the burden of living with their life-long illness. This phenomenon has been identified in patients with other long-term conditions, e.g. cancer, Irritable Bowel Disease, and Diabetes. In type 1 and 2 diabetes elevated DSD is associated with poorer clinical outcomes, and effective interventions can reduce diabetes distress. Patient involvement in the development of patient generated outcome measures (PGOM's) is important, as they may have different perspectives about their health condition that researchers and/or health care professionals may not have considered. Previous secondary data analysis of patient interviews has suggested that DSD does seem to exist in people with RA, as an entity distinct from other forms of psychological difficulties.

Objectives: The aim of this study was to develop a PGOM, based on previously reported domains of distress, to identify DSD in people with RA for use in clinical and research practice. The study aimed to involve patients in the development of the new outcome measure.

Methods: A three-phase qualitative study was conducted. In Phase 1 items were generated from secondary data analysis of patient interviews. In Phase 2, a focus group of people with RA were consulted with the aim to establish initial face and content validity of the measure and perform item reduction. In Phase 3 , individual cognitive interviews $(n=9)$ with people with RA were conducted to further establish face and content validity of the Scale, refine items if necessary and ensure the questionnaire =made sense' to participants. A psychometrician was consulted to consider the development of the new Scale.

Results: In Phase 1, 44 items were initially created to form the Rheumatoid Arthritis Distress Scale (RADS). After Phase 2 and 3 focus group and cognitive interviews respectively, items were reduced from 44 to 39 and three additional supplementary questions were created, to include items such as time since diagnosis and disease activity. Dimensions were classified into five domains of RA distress. Overall participants reported the content of the RADS to be clear and relevant, and that DSD is a valid concept in RA, distinct from clinical depression or anxiety

Conclusion: DSD appears to be an important concept in RA. The 39-item RADS currently demonstrates acceptable face and content validity in this patient group. It may be beneficial to establish face and content validity in a more diverse patient sample before proceeding with further psychometric testing. The RADS may be a useful tool for healthcare professionals to identify DSD in patients with RA. Direct patient involvement and their commitment have been instrumental in the development of new outcome measures.

Acknowledgement: This work was supported by King's College London and submitted in partial fulfilment for the MSc Degree in Advanced Neuromusculoskeletal Physiotherapy.

Disclosure of Interests: None declared

DOI: 10.1136/annrheumdis-2019-eular.2806

\section{THU0100 \\ PHYSICAL FUNCTION IN RA PATIENTS IN REMISSION UNDERGOING TAPERING AND/OR STOPPING OF} DMARDS

Marlene Stephan ${ }^{1}$, Koray Tascilar ${ }^{1}$, Melanie Hagen ${ }^{1}$, Judith Haschka ${ }^{2}$, Michaela Reiser ${ }^{1}$, Fabian Hartmann ${ }^{1}$, Arnd Kleyer ${ }^{1}$, Axel Hueber ${ }^{3}$,

Bernhard Manger ${ }^{1}$, Camille Figuereido ${ }^{4}$, Jayme Cobra ${ }^{4}$, Hans-Peter Tony ${ }^{5}$, Stephanie Finzel ${ }^{6}$, Stefan Kleinert ${ }^{7}$, Joerg Wendler ${ }^{7}$, Florian Schuch ${ }^{7}$, Monika Ronneberger ${ }^{7}$, Martin Feuchtenberger ${ }^{8}$, Martin Fleck ${ }^{9}$, Karin Manger ${ }^{10}$, Wolfgang Ochs ${ }^{11}$, Matthias Schmitt-Haendle ${ }^{11}$, Hanns-Martin Lorenz ${ }^{12}$, Hubert Nuesslein ${ }^{13}$, Rieke Alten ${ }^{14}$, Jörg Henes ${ }^{15}$, Klaus Krueger ${ }^{16}$, Georg Schett ${ }^{1}$, Jürgen Rech ${ }^{1}$. ${ }^{1}$ FAU Uniklinik Erlangen, Medizinische Klinik 3, Rheumatologie and Immunologie, Erlangen, Germany; ${ }^{2}$ Medical University of Vienna, St. Vincent Hospital, Vinforce Study Group, Vienna, Austria; ${ }^{3}$ Soziastiftung Bamberg, Medizinische Klinik III: Nieren- und Hochdruckkrankheiten, Rheumatologie, Osteologie, Akutgeriatrie, Bamberg, Germany; ${ }^{4}$ Institutio de Rheumatologia, Sao Paolo, Brazil; ${ }^{5}$ Universität Würzburg, Innere Medizin 2, Würzburg, Germany; ${ }^{6}$ University Medical Center Freiburg, Rheumatology and Clinical Immunology, Freiburg, Germany; ${ }^{7}$ Praxisgemeinschaft Rheumatologie - Nephrologie, Erlangen, Germany, ${ }^{8}$ Klinikum Burghausen, Burghausen, Germany; ${ }^{9}$ Asklepios Medical Center Baad Abbach, Department of Rheumatology and clinical Immunology, Bad Abbach, Germany, ${ }^{10}$ Rheumatologische Praxis Bamberg, Bamberg, Germany; ${ }^{11}$ Rheuma-Praxis Bayreuth, Bayreuth, Germany; ${ }^{12}$ University of Heidelberg, Department of Hematology and Rheumatology, Heidelberg, Germany, ${ }^{13}$ Rheuma Praxis Nürnberg, Nürnberg, Germany; ${ }^{14}$ Schlosspark Klinik Berlin, Innere Medizin und Rheumatologie, Berlin, Germany; ${ }^{15}$ University of Tübingen, Centre for Interdisciplinary Clinical Immunology, Tübingen, Germany, ${ }^{16}$ Rheumatologische Praxis München, München, Germany

Background: Several studies including our own RETRO study have shown that tapering or stopping disease modifying anti-rheumatic drugs (DMARDs) in rheumatoid arthritis (RA) patients in sustained remission is feasible (1-3). However, tapering/stopping bears the risk of decline in physical function as some patients may relapse and face increased disease activity.

Objectives: Here we analysed the impact of tapering or stopping DMARD treatment on the physical function of RA patients, who were randomized into continuation, tapering or stopping DMARD treatment in the RETRO study. Methods: RETRO is a multicentre, parallel-group phase 3 trial in which RA patients in stable DAS-28-ESR remission were randomized to (i) DMARD tapering, (ii) stopping DMARDs after a 24-week-taper or (iii) control strategy that continued DMARDS. ${ }^{1,2,3} \mathrm{HAQ}$ and DAS-28 scores were measured at $0,3,6,9$ and 12 months. ${ }^{1,2}$ Functional worsening was defined as a $\mathrm{HAQ}$ increase of $>0.25$. We calculated incidences of functional worsening (per 100 person-months) in each treatment group with 95\% Poisson confidence intervals and plotted event-free survival by treatment arm. The effect of treatment reduction strategy on functional worsening was assessed in a recurrent-event Cox regression model with control, taper or taper/stop group as the predictor.

Results: 201 patients were analysed. In 44 patients functional worsening was observed. Incidence $(95 \% \mathrm{Cl})$ of functional worsening was in the control 1.48 (0.77-2.59), taper $1.74(0.95-2.92)$ and taper/stop arm 1.96 (1.16-3.10). The incidences suggest higher probability of functional worsening in tapering and/or stopping DMARDs, however at the end of study, functional worsening was similar among the groups (Figure). Thus, in comparison to the control group, hazard ratio $(\mathrm{HR})(95 \% \mathrm{Cl})$ for functional worsening was $1.21(0.56-2.62)$ in the taper arm and $1.32(0.76$ 2.60) in the taper/stop arm.

Conclusion: Point estimates and survival curves show that functional decline after tapering or stopping DMARDs in RA patients with stable remission is small. Although the incidence figures suggest a trend these results do not reject with good certainty the null hypothesis of no worsening in functional status.



Abstract THU0100 - Figure 1

REFERENCE:

[1] Haschka, J. et al. 2016; 2 Rech, J. et al. 2016; 3 Hagen, M. et al. 2018 